1 Pan-transcriptomic analysis identifies coordinated and orthologous

2 functional modules in the diatoms Thalassiosira pseudonana and

$3 \quad$ Phaeodactylum tricornutum

4

5 Justin Ashworth ${ }^{1}$, Serdar Turkarslan ${ }^{1}$, Micheleen Harris ${ }^{1}$, Mónica V. Orellana ${ }^{1,2}$, Nitin S. Baliga ${ }^{1,3}$

$6 \quad{ }^{1}$ Institute for Systems Biology, Seattle, WA USA

$7 \quad{ }^{2}$ Polar Science Center, University of Washington, Seattle, WA USA

$8{ }^{3}$ Department of Microbiology, University of Washington, Seattle, WA USA

Abstract

11 Diatoms are important primary producers in the ocean that thrive in diverse and dynamic

12 environments. Their survival and success over changing conditions depend on the complex

13 coordination of gene regulatory processes. Here we present an integratedanalysis of all publicly

14 available microarray data for the diatoms Thalassiosira pseudonana and Phaeodactylum

15 tricornutum. This resource includes shared expression patterns, gene functions, and cis-

16 regulatory DNA sequence motifs in each species that are statistically coordinated over many

17 experiments. These data illustrate the coordination of transcriptional responses in diatoms over

18 changing environmental conditions. Responses to silicic acid depletion segregate into multiple

19 distinctly regulated groups of genes, regulation by heat shock transcription factors (HSFs) is

20 implicated in the response to nitrate stress, and distinctly coordinated carbon concentrating,

$21 \mathrm{CO}_{2}$ and $\mathrm{pH}$-related responses areapparent. Fundamental features of diatom physiology

22 aresimilarly coordinated between two distantly related diatom species, including the regulation

23 of photosynthesis, cellular growth functions and lipid metabolism. These integrated data and

24 analysescan be explored publicly (http://networks.systemsbiology.net/diatom-portal/). 
26 Diatoms are important primary producers in marine ecosystems (Armbrust, 2009; Tsuda et al.,

27 2003), and their ability and capacity to physiologically adjust to changing ocean conditions is

28 critical to their ecological success, both now and in the future. The heterokonts (including

29 diatoms) are phylogenetically distinct from other clades, and representrelatively undiscovered

30 genomic and physiological territory. Recent studies of diatom genomes (Armbrust et al., 2004;

31 Bowler et al., 2008), transcriptomes and proteomes(Allen et al., 2008; Ashworth et al., 2013;

32 Brembu et al., 2011; Carvalho et al., 2011; Chauton et al., 2013; Hook and Osborn, 2012;

33 Kustka et al., 2014; Levitan et al., 2015; Mock et al., 2008; Nymark et al., 2013, 2009; Sapriel et

34 al., 2009; Shrestha et al., 2012; Thamatrakoln et al., 2013, 2012; Valle et al., 2014)hint at

35 complex molecular and regulatory programs that control diatom physiology and acclimation to a

36 variety of different environmental conditions. However, the specific coordination and regulation

37 of these molecular and adaptive processes in diatoms remains largely unknown for multiple

38 reasons: i) the size and complexity of diatom genomes and their molecular responses to

39 change, ii) their genetic uniqueness and lack of sufficient homology in comparison to other well-

40 studied clades, iii) low-throughput experimental genetics approaches, and iv) insufficient data

41 and analysis methods to identify concurrent yet distinct molecular and regulatory pathways

42 operating simultaneously under various conditions.

43 The integration and analysis of data collected through many different transcriptomic

44 experiments can be used to discover fundamentally coordinated, conditional, and distinct

45 molecular responses that are reflective of gene regulatory processes and can not be discovered

46 through individual experiments (Brooks et al., 2014; Danziger et al., 2014; Reiss et al., 2006).

47 Data-driven approaches for the discovery of molecular coordination may be particularly useful in

48 the case of diatoms, given the size and novelty of their genomes, transcriptomes and

49 proteomes.To systematically discover and identify modules of putatively coordinated and 
50 functionallyrelated diatom genes, we aggregated all available microarray expression data for the

51 model diatoms T. pseudonana and P. tricornutum, and performed hierarchical clustering (Eisen

52 et al., 1998) and motif-guided biclustering (Reiss et al., 2006) over many experimental

53 conditions. Highlights of this analysis in the context of specific conditions and functions are

54 discussed herein, and the complete results have been made available for further use and

55 exploration in a web portal at the following url: http://networks.systemsbiology.net/diatom-portal/.

\section{Data Sources and Methods}

57 Integrated diatom transcriptomic dataset.Transcriptome-wide microarray expression data $T$.

58 pseudonana used in this analysis included: silica, iron, and nitrogen limitation, low temperature

59 and elevated $\mathrm{pH}$ (Mock et al., 2008), exposure to pollutant and mutagen

60 benzo[a]pyrene(Carvalho et al., 2011), iron starvation (Thamatrakoln et al., 2012), silica re-

61 supplementation (Shrestha et al., 2012), diel growth from exponential to stationary phase

62 (Ashworth et al., 2013), and growth at moderate and elevated $\mathrm{CO}_{2}$ levels under moderate and

63 elevated light (Gene Expression Omnibus (GEO) accession \#GSE57737).Transcriptome-wide

64 microarray expression data for $P$. tricornutum used in this analysis included: silica limitation

65 (Sapriel et al., 2009), acclimation to high light (Nymark et al., 2009), exposure to cadmium

66 (Brembu et al., 2011), acclimation to light and dark cycles (Chauton et al., 2013), exposure to a

67 panel of pollutants (Hook and Osborn, 2012), darkness and re-illumination (Nymark et al.,

68 2013), exposure to red, blue and green light (Valle et al., 2014). All public microarray data were

69 downloaded from GEO, converted to $\log _{2}$ expression ratios vs. within-experiment control

70 samples, and aggregated by common transcript identifiers for each species. The normalization

71 performed within these independent experimental datasets was preserved in order to reflect

72 previous findings; further approaches to normalize these datawere explored in conjunction with

73 various distance metrics and hierarchical clustering methods, as described below in the section:

74 Co-Expression Clustering. 
75 Genome information, protein annotations, functional enrichment analysis and

76 predictions of orthology. The genomes, gene, transcript and protein models, and functional

77 annotations for each diatom species (T. pseudonana:version 3; P. tricornutum:version 2) were

78 downloaded from the Joint Genome Institute (JGI) Genome Portal (Grigoriev et al., 2011).

79 Existing protein functional annotations were supplemented with significant matches to the

80 Conserved Domain Database (Marchler-Bauer et al., 2015). The enrichment of GO terms

81 (biological process) across all co-expression clusters was computed from existing JGI GO

82 annotations using a hypergeometric test and multiple hypothesis correction by the Benjamini-

83 Hochberg method (Benjamini and Hochberg, 1995). Putative orthologous proteins between

84 diatom species were inferred using a pairwise reciprocal best BLASTp(Altschul et al., 1990)

85 approach with an E-value cutoff of $1 \times 10^{-10}$. Significantly orthologous co-expression clusters

86 between species were identified by computing the hypergeometric probability of drawing

87 intersections of orthologous genes (Kalinka, 2013) and multiple hypothesis correction

88 (Benjamini and Hochberg, 1995).

89 Co-expression clustering. The co-expression of transcripts across all included experiments

90 was assessed using a Pearson correlation distance metric over all corresponding $\log _{2}$

91 expression ratios for each pair of transcripts.Fast agglomerative hierarchical clustering(Müllner,

92 2013) was used to generate a hierarchical tree of correlated transcripts, and ten thousand-fold

93 multi-scale bootstrap resampling (Suzuki and Shimodaira, 2006) was used to estimate the

94 significance and robustness of hierarchical subclusters to simulated noise and variation in the

95 data.For efficiency on large transcriptomes, all pairwise distance calculations, hierarchical

96 clustering using the fastclusterc++ library (Müllner, 2013), and performance-critical functions of

97 the pvclust R package (Suzuki and Shimodaira, 2006) were computed using compiled c++ code

98 that is available for download. The false discovery rate of cluster-level changes in expression

99 over categorical conditions was computed based on empirical distributions $(n \geq 10,000)$ of

100 clusters composed of randomly-selected transcripts for each cluster size over each condition, 
with multiple hypothesis correction to account for total number of clusters. Significantly shared DNA sequence motifs in the upstream promoter regions of genes co-occurring in hierarchical

103 co-expression clusters were detected using MEME (Bailey and Elkan, 1994) and compared to 104 databases of known motifs using TOMTOM (Gupta et al., 2007), both of which are part of the 105 MEME software suite (Bailey et al., 2009).

106 DNA motif-guided biclustering. The simultaneous clustering of genes based on i) co107 expression over subsets of experimental conditions, ii) shared upstream non-coding DNA 108 sequence patterns (possible cis-regulatory motifs), and iii) known gene and protein associations 109 (Szklarczyk et al., 2011) was performed using version 4.9.21 of the R package cMonkey (Reiss 110 et al., 2006). For biclustering using the cMonkey algorithm, the data were row-normalized as 111 described in (Reiss et al., 2006). The bottom twenty-five percent least variant transcripts over all 112 conditions were excluded from this analysis for computationaland algorithmic efficiency. DNA 113 sequences up to four hundred base pairs upstream of gene model start sites were iteratively 114 searched using MEME (Bailey et al., 2009) for significantly occurring DNA sequence motifs in 115 the putative promoters of co-expressed genes. The cMonkey algorithm was run for two 116 thousand iterations to generate biclusters with a mean of thirty genes per cluster.

\section{Results}

118 Pan-transcriptomic clustering identifies separately coordinated groups of genes within 119 singular condition-specific responses. Through integrative, whole-genome multi-experiment 120 clustering (Fig. 1), numerous distinctly and significantly co-expressed sets of functionally-related 121 transcripts were discovered in T. pseudonana and $P$. tricornutum (Table 1, Table S1). In 122 addition, lists of transcripts that were significantly affected in individual previous 123 experimentswere segregated into separate anddistinctly coordinated groups of genes. For 124 example, transcripts whose expression increased in silica-limited T. pseudonana diatoms (Mock 125 et al., 2008) represent at least three distinct transcriptional and physiological response 
mechanisms (Fig. S1). Three distinct clusters of co-expressed genes contain the top five

exclusively under silica limitation in previous experiments, in addition to several other silica-

sensitive transcripts(Mock et al., 2008). These functions appear to be divided into silica and

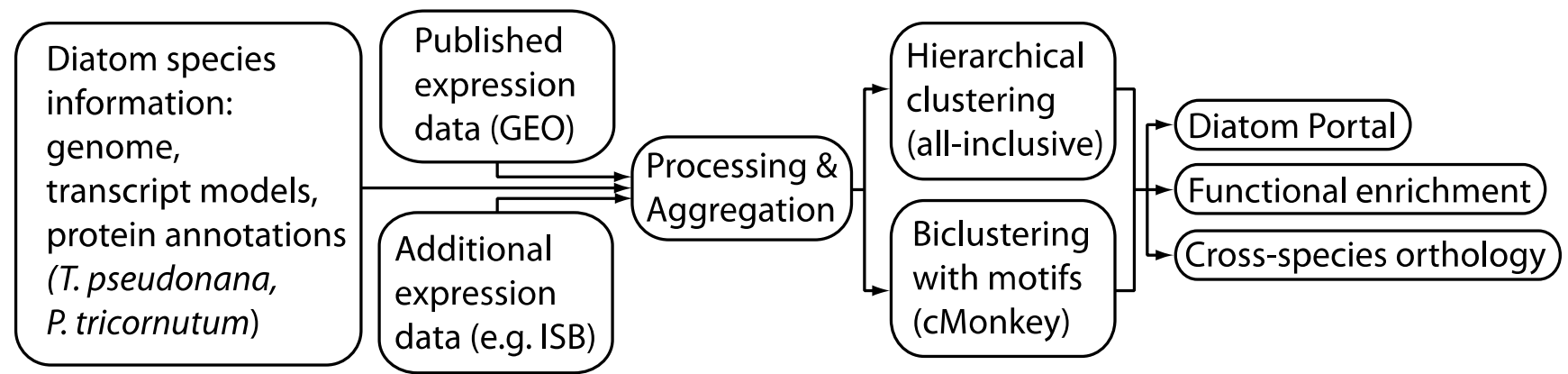

Figure 1. Pan-transcriptomic discovery of co-expressed functional modules in diatoms.

Table 1. Clustering statistics.

\begin{tabular}{|l|r|r|}
\hline & T. pseudonana & P. tricornutum \\
\hline Transcript models included in analysis & 12,114 & 10,352 \\
\hline Protein models with GO annotations (biological process) $^{1}$ & 3,818 & 3,195 \\
\hline Microarray series (\# of distinct samples) $^{1}$ & $8(56)$ & $7(123)$ \\
\hline Hierarchical clusters (height-based selection) Significantly enriched upstream DNA motifs in clusters & \\
\hline Bootstrap-supported hierarchical subclusters (pvclust) $^{3}$ & 500 & 500 \\
\hline Transcript models included in biclustering (cMonkey) $^{4}$ & 593 & 143 \\
\hline Biclusters (cMonkey) & 899 & 1,006 \\
\hline Significantly enriched upstream DNA motifs in biclusters $^{2}$ & 8,771 & 7,708 \\
\hline
\end{tabular}

${ }^{1} \mathrm{JGI}$ version 3 models and annotations for T. pseudonana; JGI version 2 for $P$. tricornutum.

${ }^{2}$ MEME E-value $\leq 1 \times 10^{-3}$.

${ }^{3}$ Approximately unbiased bootstrap $P$-value $\geq 90 \%, n \geq 3$ transcripts.

${ }^{4}$ The top $75 \%$ most variant transcripts were included in biclustering.

Pan-transcriptomic clustering also identified clusters of tightly co-expressed genes for which evidence of direct co-regulation is present in upstream promoter regions. For example, among thousands of transcripts that significantly changed in expression between exponential and stationary/nutrient limited cultures in a previous microarray experiment (Ashworth et al., 
2013), multi-experiment clustering identified one in particularthat includes nitrate and nitrite

147 transporters (protein ids 27414, 269274, 3393), nitrite reductases $(25299,26941,262125), a$

148 homolog of the DnaJ/Hsp40protein (24341), a peroxisomal membrane protein (37980), and

149 several others putatively involved in the acclimation to growth-limiting conditions (Fig. 2).The

150 mean expression of these transcripts was increased during nitrogen starvation, darkness,

151 growth under high light, and iron limitation (Fig. 2B). A shared putative cis-regulatory DNA

152 sequence motif occurs in the upstream promoter region of most $(25 / 30 ; 83 \%)$ of the genes in

153 this cluster (MEME E-value: $1.3 \times 10^{-9}$ ). This motif resembles a conserved heat shock element

154 (HSE)DNA sequence bound by heat shock transcription factors in eukaryotes(Pelham, 1985),

155 including one from model plant species Arabidopsis thaliana (Fig. 2C) (Franco-Zorrilla et al.,

156 2014).Pan-transcriptomic clustering also identified transcriptional coordination of transcripts that

157 were not specifically targeted by experimentalconditions in previous experiments: two bootstrap-

158 supported clusters contain T. pseudonana transcripts that encode several carbon-concentrating

159 proteins that were recently discovered to increase in abundance in carbon-limited cultures

160 (Kustka et al., 2014) and to decrease in abundance under elevated $\mathrm{CO}_{2}$ (Hennon et al.,

161 2015)(Fig. S2).

162
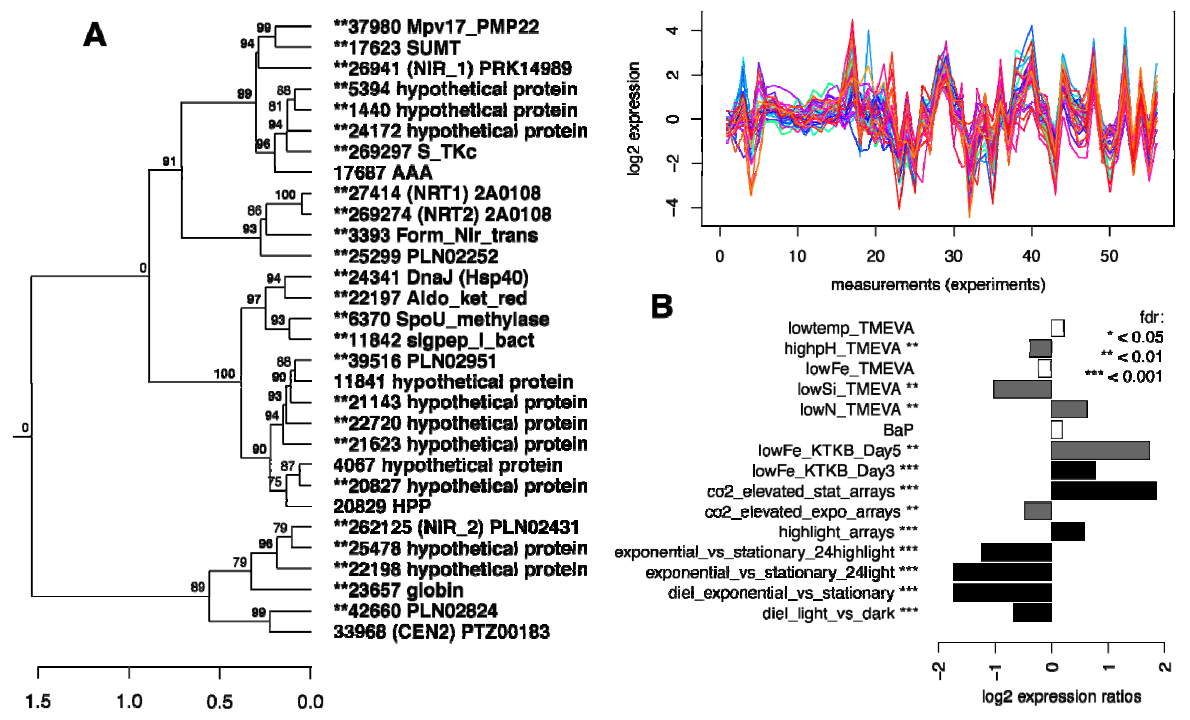

C

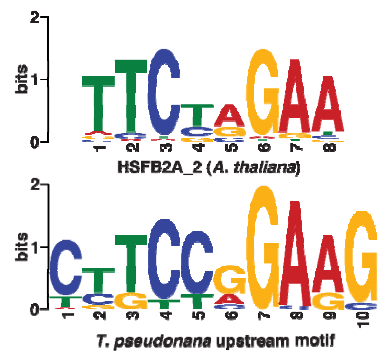


Figure 2. A putatively co-regulated cluster of genes responsible for nitrate assimilation and stress response in $T$. pseudonana.A tightly co-expressed cluster of transcripts (A) related to nitrate assimilation and potential stress-related mechanisms is significantly increased in expression during stationary, nutrient-limited conditions, high light, and iron and nitrate limitation (B). A shared putative cis-regulatory DNA motif (C) found in the upstream regions of most of the genes in this cluster is similar to the known binding site of a heat shock transcription factor found in $A$. thaliana. The presence of the discovered motif in individual gene promoters is indicated by asterisks in (A).

\section{Newly discovered condition-specific clusters.Multi-experiment clustering resulted in the} identification of new putative modules of co-expressed and co-regulated genes with shared functions and condition-specific transcriptional responses. For example, a cluster of $P$. tricornutum transcripts encoding several putative enzymes was tightly co-expressed over all conditions (bootstrap $P$-value $=91 \%$ ), significantly differentially expressed over a range of conditions, and significantly increased in expression upon exposure to oil (Hook and Osborn, 2012) (Fig. S3A). A cluster of $T$. pseudonana transcripts encoding a silaffin protein, extracellular domains, peptidases and signaling proteins was tightly co-expressed over a range of conditions; The mean expression of these transcripts was significantly decreased at high $\mathrm{pH}$ and low silica, and significantly increased under elevated $\mathrm{CO}_{2} / \mathrm{low} \mathrm{pH}$ and during exponential growth (Fig.S3B).

Diatom species share orthologous clusters of co-expressed transcripts.Comparison of coexpression clusters between T. pseudonana and $P$. tricornutum revealed seventeensignificantly homologous clusters of transcripts between these two distantly related diatom species. Despite the different kinds of experiments from which transcriptome measurements were derived for the two species, similarly coordinated expression for groups of orthologous gene functions indicates fundamental processes whose transcriptional regulation is conserved between these diatoms. Among these conserved functions and processes are fatty acid metabolism (Fig 3), light harvesting complexes (Fig. S4A), photosynthesis (Fig. S4B), protein biosynthesis (ribosomal 
A

\section{P. tricornutum}

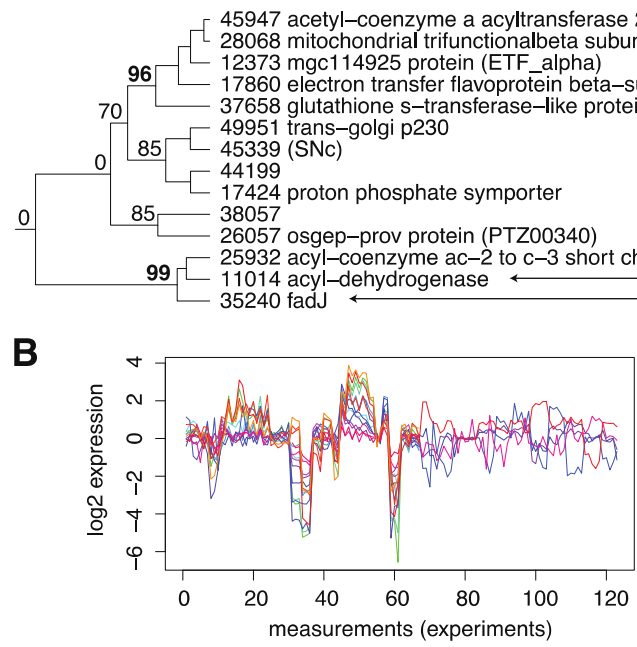

C

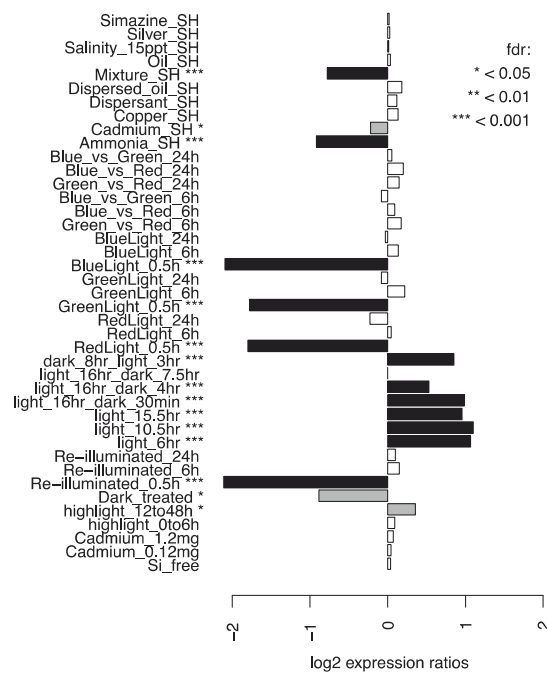

\section{T. pseudonana}
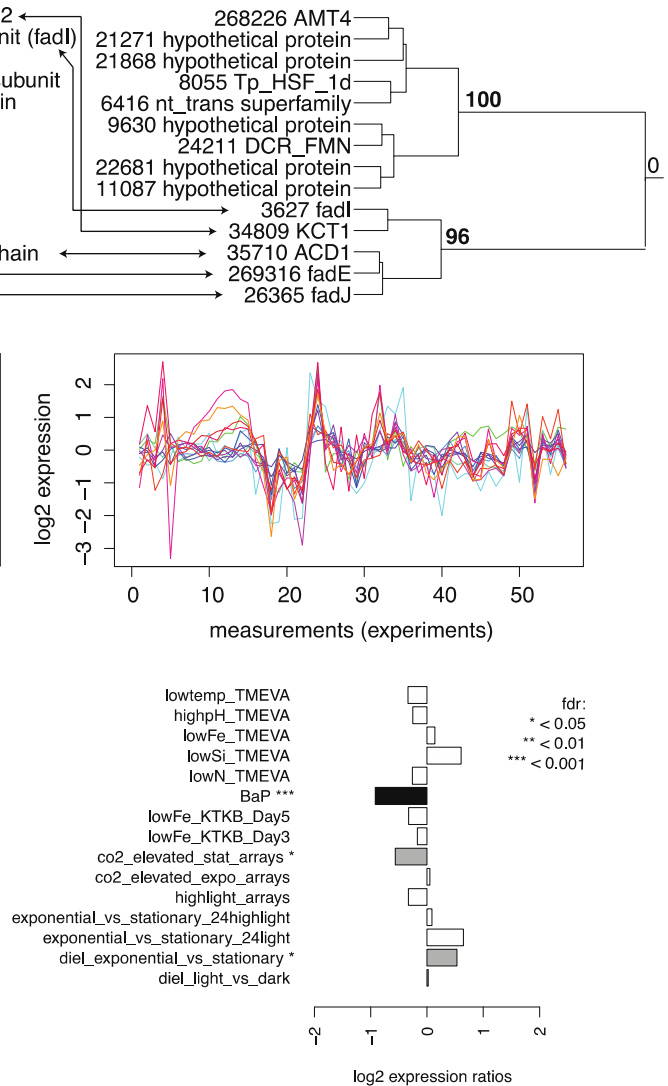

D

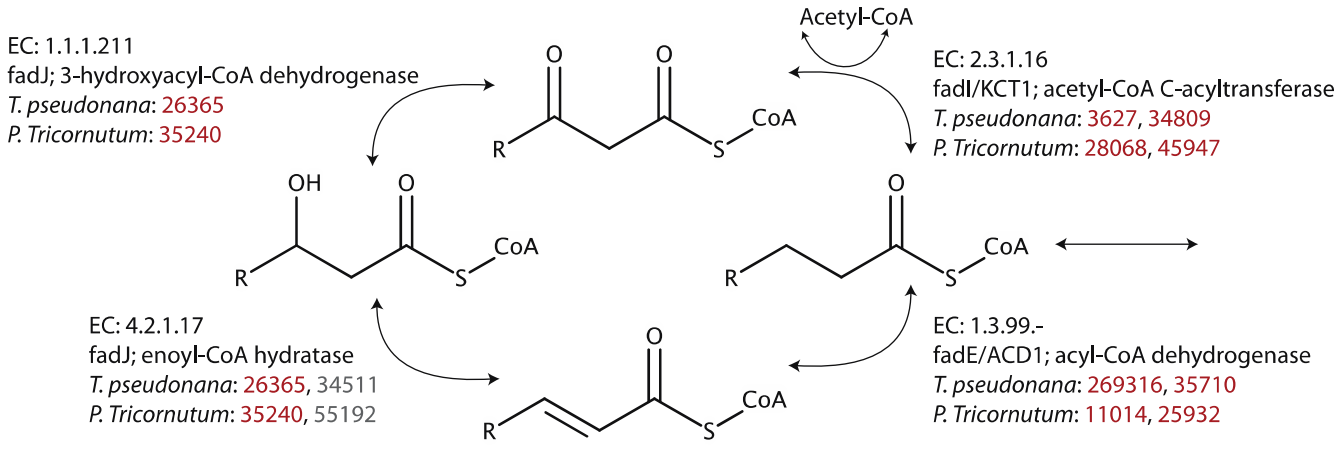

Figure 3. Conserved enzymes involved in fatty acid metabolism in both T. pseudonana and $P$. tricornutum are tightly co-expressed over large numbers ofexperimental conditions. 
A)Hierarchical clusters (dendrograms) from both species containing transcripts for orthologous enzymes in the fatty acid elongation and degradation ( $\beta$-oxidation) cycle (D). Arrows indicate orthologous proteins and selected branches are labeled with transcriptome-wide bootstrap $P$ values. B)Raw expression profile for these gene clusters over many conditions. C) Mean changes in expression over many conditions. Asterisks and shading indicate the significance (false discovery rate) for the magnitude of these changes. D) The fatty acid elongation and degradation ( $\beta$-oxidation) cycle in T. pseudonana and P. tricornutum. Enzyme Commission (E.C.) numbers, enzyme names, and the orthologous enzymes in each species are listed. Red numbers indicate transcripts present in orthologous co-expression clusters (A).

Table 2. Orthologous hierarchical clusters shared between species. Hierarchical coexpression clusters from both species were compared to detect significantly orthologous clusters of protein-coding transcripts. The hypergeometric intersection method of (Kalinka, 2013) was used to assess significance, with Benjamini-Hochberg correction for multiple hypotheses.

\begin{tabular}{|c|c|c|c|c|c|c|l|}
\hline \multicolumn{2}{|l}{ P. tricornutum } & \multicolumn{2}{l|}{ T. pseudonana } & & & & \\
\hline Cluster & Size & Cluster & Size & Orthologs & $\boldsymbol{p}$-value & FDR & OrthologicalFunction \\
\hline 151 & 46 & 47 & 46 & 29 & $1.06 \mathrm{E}-54$ & $2.66 \mathrm{E}-49$ & ribosomal proteins \\
\hline 111 & 51 & 22 & 66 & 20 & $8.69 \mathrm{E}-43$ & $2.17 \mathrm{E}-37$ & light harvesting complexes \\
\hline 201 & 60 & 220 & 85 & 22 & $1.53 \mathrm{E}-29$ & $3.82 \mathrm{E}-24$ & RNA processing and nucleolar proteins \\
\hline 183 & 26 & 199 & 42 & 14 & $2.15 \mathrm{E}-26$ & $5.37 \mathrm{E}-21$ & proteasomal proteins \\
\hline 146 & 37 & 47 & 46 & 16 & $1.04 \mathrm{E}-25$ & $2.60 \mathrm{E}-20$ & ribosomal proteins \\
\hline 146 & 37 & 46 & 25 & 12 & $1.25 \mathrm{E}-21$ & $3.13 \mathrm{E}-16$ & ribosomal proteins \\
\hline 97 & 108 & 82 & 94 & 14 & $1.70 \mathrm{E}-20$ & $4.25 \mathrm{E}-15$ & cytokinesis \\
\hline 151 & 46 & 46 & 25 & 11 & $4.36 \mathrm{E}-18$ & $1.09 \mathrm{E}-12$ & ribosomal proteins \\
\hline 177 & 31 & 24 & 73 & 9 & $9.41 \mathrm{E}-14$ & $2.35 \mathrm{E}-08$ & porphyrin biosynthesis \\
\hline 176 & 19 & 24 & 73 & 8 & $2.60 \mathrm{E}-13$ & $6.50 \mathrm{E}-08$ & porphyrin biosynthesis \\
\hline 100 & 70 & 92 & 93 & 6 & $5.43 \mathrm{E}-12$ & $1.36 \mathrm{E}-06$ & cell cycle, cell division, frustule \\
\hline 200 & 35 & 220 & 85 & 9 & $1.52 \mathrm{E}-10$ & $3.80 \mathrm{E}-05$ & RNA processing and nucleolar proteins \\
\hline 108 & 34 & 440 & 14 & 5 & $8.03 \mathrm{E}-10$ & $2.01 \mathrm{E}-04$ & fatty acid metabolism \\
\hline 96 & 103 & 82 & 94 & 9 & $1.25 \mathrm{E}-09$ & $3.13 \mathrm{E}-04$ & chromatin regulation \\
\hline 134 & 21 & 41 & 53 & 6 & $2.33 \mathrm{E}-09$ & $5.82 \mathrm{E}-04$ & ribosomal proteins and tRNAs \\
\hline 243 & 38 & 220 & 85 & 7 & $7.93 \mathrm{E}-08$ & $1.98 \mathrm{E}-02$ & chromatin regulation \\
\hline 175 & 28 & 15 & 67 & 5 & $1.58 \mathrm{E}-07$ & $3.94 \mathrm{E}-02$ & glycolysis \\
\hline
\end{tabular}

214 biclustering.For several prokaryotic and some eukaryotic species it is possible to discover and

215 refine groups of genes whose co-expression and regulation is explained by the presence of

216 shared cis-regulatory DNA sequence motifs (Brooks et al., 2014; Danziger et al., 2014;

217 Peterson et al., 2014; Reiss et al., 2006). Applying the cMonkey motif-guidedbiclustering

218 methodology(Reiss et al., 2006) to combined genomic and transcriptomic data for $T$.

219 pseudonana and $P$. tricornutum resulted in biclusters of functionally related co-expressed genes

220 in which shared and potentially meaningful cis-regulatory DNA motif patterns were found in 
221 putative upstream promoter regions (Table 1 and Table S2). Two examples are a bicluster of $T$.

222 pseudonana genes putatively involved in tRNA and protein synthesis and a bicluster of $P$.

223 tricornutum genes putatively involved in protein processing and amino acid metabolism

224 (Fig.S5).Significantly enriched DNA sequence motifs found in these biclusters resemble the 225 measured DNA binding sequences for Myb and PIF transcription factors in Arabidopsis thaliana

226 (Fig. S5C and S5D, respectively) (Franco-Zorrilla et al., 2014). The significantly enriched cis-

227 regulatory sequences in the upstream regions of the genes in these clusters may be key to the

228 transcriptional regulation of co-expressed diatom genes. However, these inferences must be

229 experimentally investigated, and additional data will be required to accurately describe and

230 model diatom gene regulatory networks, including true transcriptional start sites, known

231 transcription factor binding site and other cis-regulatory sequences, and genome-wide

232 transcriptional factor-DNA binding measurements. Additionally, pre- and post-transcriptional and

233 post-translational regulatory mechanisms such as microRNAs, protein signaling, nuclear

234 translocation and metabolite levels may also factor significantly into the regulation of physiology

235 in diatoms.

236 Exploration of data and comprehensive results: The Diatom Portal.The aggregated data

237 and clustering described and discussed here have been incorporated into a public web portal

238 (The Diatom Portal) for further exploration and analysis. This web interface includes gene,

239 transcript and protein level information for fully sequenced and transcriptionally profiled diatoms

240 (currently T. pseudonana and P. tricornutum), a lightweight genome context browser, and the

241 results of hierarchical expression clustering and motif-directed biclustering over many

242 aggregated datasets and conditions (Fig. 4). The contents ofthis portal are organized into gene

243 transcripts, clusters of co-expressed genes, and detected potential DNA cis-regulatory

244 sequence motifs. These can be explored by using a variety of filters, or searched using a variety

245 of search terms including JGI protein identification numbers, annotation keywords, and GO 
246 terms. There are two primary record typesrepresented in the portal: Genes and Clusters. Pages

247 for individual genes contain a genome browser (Fig. 4A), gene and transcript model

248 information, synonymous external identifiers, other most highly correlated transcripts (Fig. 4B),

249 conserved domains (Fig. 4C), predicted orthologous genes detected in other diatoms and plant

250 species (Fig. 4D), previews of co-expression clusters in which the transcript occurs (Fig. 4E),

251 KEGG mapping and gene ontology (GO) terms. Pages for individual co-expression clusters

252 contain groups of gene transcripts whose expression was correlated over many experiments,

253 changes in expression over categorical conditions, GO term enrichments, and potential cis-

254 regulatory DNA motifs detected in the upstream promoter regions of the genes occurring in the

255 cluster. The details and position weight matrices (PWMs) for these motifs can also be

256 downloaded in MEME format for comparison against databases of known motifs (e.g. TOMTOM

257 (Gupta et al., 2007)). The aggregate data set used for expression clustering can also be

258 downloaded for additional or independent analysis. The goal of this Diatom Portal is to facilitate

259 discoveries, hypothesis generation, collaboration and continued data integration within the

260 diatom research community in order to accelerate the advancement of the science and

261 understanding of diatom biology and gene regulation. For example, the incorporation of

262 additional transcriptomic data (including mRNA-sequencing data and the MMETSP (Keeling et

263 al., 2014)) as it becomes available will increase the resolution and conditionality of gene

264 expression clustering, and continued cross-species analysis will expand the set of conserved,

265 related and unique regulatory features and coordination that can be detected and inferred within

266 the diatom clade. 


\section{Diatom Portal}

268895
Enter your search term. e.g "268895", "lipase", "G0:0003755" etc.

Put quotes around phrases to match all the words: "lipase superfamily" . You can require or exclude terms using + and -

\section{5 (SIT1) Silic_transp superfamily}

Thalassiosira pseudonana

View Edit Manage display Track Log

A Genome Browser

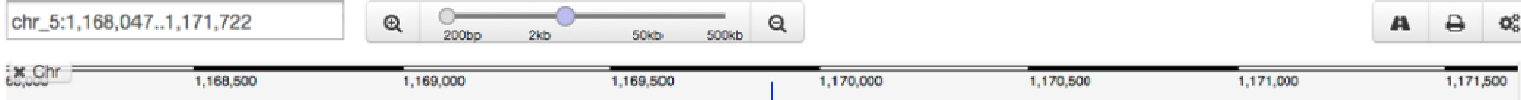

|

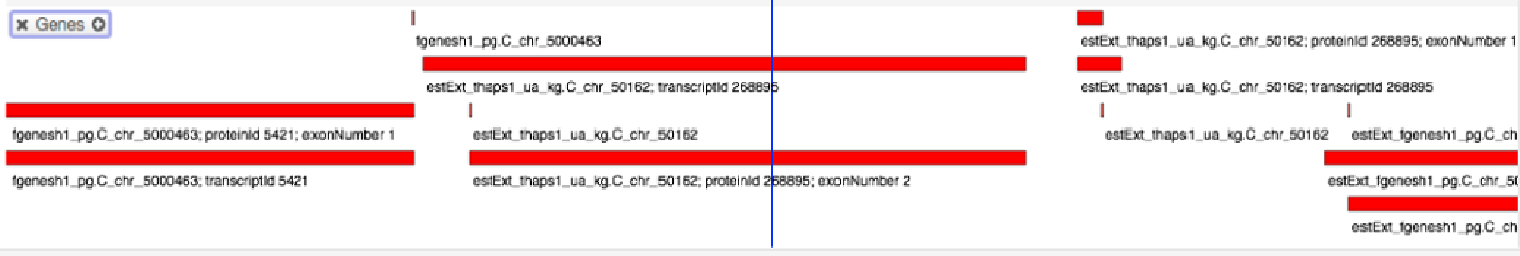

B Most Highly Correlated Transcripts

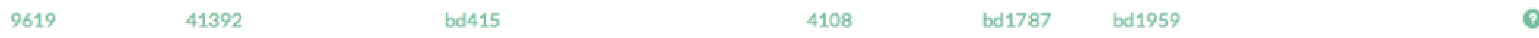

hypothetical protein(SIT2) Silic_transp superfamily(bd415) arom_aa_hydroxylase superfamilyhypothetical protein(bd1787) GLTP(bd1959) NA

$\begin{array}{llllll}\mathbf{0 . 8 7 0 5} & 0.8593 & 0.859 & 0.8515 & 0.8497 & \mathbf{0 . 8 4 4 7} \\ \text { bd1941 } & 21968 & \text { bd1808 } & \text { bd721 } & \\ \text { (bd1941) NA } & \text { hypothetical protein } & \text { (bd1808) NA } & \text { (bd721) NA } & \\ 0.8377 & 0.8313 & \mathbf{0 . 8 2 6 3} & \mathbf{0 . 8 2 5} & \end{array}$

C Conserved Domains

\begin{tabular}{|c|c|c|c|c|c|c|c|c|}
\hline Name & CD Accession & Definition & Superfamily & Bitscore & E-Value & From - To & Hit Type & PSSMID $^{?}$ \\
\hline Silic_transp superfamily & Q cl04286 & Silicon transporter; Silicon transporter. (i) & - & 780.964 & 0 & $1-461$ & superfamily & 146463 \\
\hline
\end{tabular}

D Homologs in Other Species

T. P. tricornutum

Pseudo-nitzschia

ONot PHATRDRAFT_23423 PHATRDRAFT_23423 ONot

available available available available avallable available

E Hierarchical Clustering

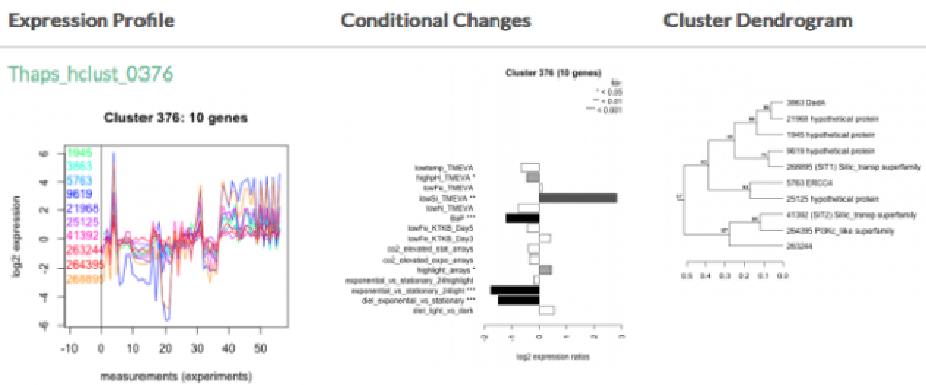

Discovered Potential cis-Regulatory Motifs

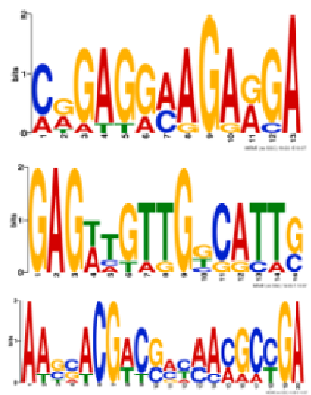


Figure 4.The Diatom Portal. This figure illustrates the Diatom Portal web interface, using search results for the SIT1 silicic acid transporter (protein id: 268895) in T. pseudonana as an example. These results include A) a lightweight genome context browser, B) highly correlated transcripts, C) detected conserved protein domains, D) putative orthologs in other related

\section{Conclusion}

276 In this work, anintegrated analysis of transcriptomic data for two model diatom species ( $T$.

277 pseudonana and P. tricornutum) overmany independent experiments resulted in the

278 comprehensive inference of coordinated and conditional transcriptional responses that are

279 indicative ofdistinctfunctional and gene regulatory processes operating robustly in the cell. The

280 clusteringand analysis of combined datasets performed here allowed the partitioning of the large

281 transcriptomes of these diatom species into distinct groups of putatively coordinatedand

282 functionally related genes that are enriched in diverse essential functions, and were not

283 previously evident in individual transcriptome experiments. The continued integration and meta-

284 analysis of genomic and transcriptomic data from diatom species will be essential to accelerate

285 the discovery molecular coordination in these complex and novel biological systems, and help to

286 inform ongoing and future studies of these and other related diatoms and microalgae.

\section{Acknowledgements}

288 This work was supported by the National Science Foundation (OCB-0928561 and MCB-

2891316206 to M.V.O. and N.S.B.) 


\section{References}

Allen, A.E., Laroche, J., Maheswari, U., Lommer, M., Schauer, N., Lopez, P.J., Finazzi, G., Fernie, A.R., Bowler, C., 2008.Whole-cell response of the pennate diatom Phaeodactylum tricornutum to iron starvation. Proc. Natl. Acad. Sci. U. S. A. 105, 10438-10443. doi:10.1073/pnas.0711370105

Altschul, S.F., Gish, W., Miller, W., Myers, E.W., Lipman, D.J., 1990. Basic local alignment search tool. J. Mol. Biol. 215, 403-410. doi:10.1016/S0022-2836(05)80360-2

Armbrust, E.V., 2009. The life of diatoms in the world's oceans.Nature 459, 185192.doi:10.1038/nature08057

Armbrust, E.V., Berges, J.A., Bowler, C., Green, B.R., Martinez, D., Putnam, N.H., Zhou, S., Allen, A.E., Apt, K.E., Bechner, M., Brzezinski, M.A., Chaal, B.K., Chiovitti, A., Davis, A.K., Demarest, M.S., Detter, J.C., Glavina, T., Goodstein, D., Hadi, M.Z., Hellsten, U., Hildebrand, M., Jenkins, B.D., Jurka, J., Kapitonov, V.V., Kröger, N., Lau, W.W.Y., Lane, T.W., Larimer, F.W., Lippmeier, J.C., Lucas, S., Medina, M., Montsant, A., Obornik, M., Parker, M.S., Palenik, B., Pazour, G.J., Richardson, P.M., Rynearson, T.A., Saito, M.A., Schwartz, D.C., Thamatrakoln, K., Valentin, K., Vardi, A., Wilkerson, F.P., Rokhsar, D.S., 2004. The genome of the diatom Thalassiosira pseudonana: ecology, evolution, and metabolism. Science 306, 79-86. doi:10.1126/science.1101156

Ashworth, J., Coesel, S., Lee, A., Armbrust, E.V., Orellana, M.V., Baliga, N.S., 2013. Genomewide diel growth state transitions in the diatom Thalassiosira pseudonana. Proc. Natl. Acad. Sci. U. S. A. 110, 7518-7523. doi:10.1073/pnas.1300962110

Bailey, T.L., Boden, M., Buske, F.A., Frith, M., Grant, C.E., Clementi, L., Ren, J., Li, W.W., Noble, W.S., 2009. MEME Suite: tools for motif discovery and searching. Nucleic Acids Res. 37, W202-W208.doi:10.1093/nar/gkp335

Bailey, T.L., Elkan, C., 1994. Fitting a mixture model by expectation maximization to discover motifs in biopolymers. Proc. Int. Conf. Intell. Syst. Mol. Biol. ISMB Int. Conf. Intell. Syst. Mol. Biol. 2, 28-36.

Benjamini, Y., Hochberg, Y., 1995. Controlling the False Discovery Rate: A Practical and Powerful Approach to Multiple Testing. J. R. Stat. Soc. Ser. B Methodol. 57, 289-300.

Bowler, C., Allen, A.E., Badger, J.H., Grimwood, J., Jabbari, K., Kuo, A., Maheswari, U., Martens, C., Maumus, F., Otillar, R.P., Rayko, E., Salamov, A., Vandepoele, K., Beszteri, B., Gruber, A., Heijde, M., Katinka, M., Mock, T., Valentin, K., Verret, F., Berges, J.A., Brownlee, C., Cadoret, J.-P., Chiovitti, A., Choi, C.J., Coesel, S., De Martino, A., Detter, J.C., Durkin, C., Falciatore, A., Fournet, J., Haruta, M., Huysman, M.J.J., Jenkins, B.D., Jiroutova, K., Jorgensen, R.E., Joubert, Y., Kaplan, A., Kröger, N., Kroth, P.G., La Roche, J., Lindquist, E., Lommer, M., Martin-Jézéquel, V., Lopez, P.J., Lucas, S., Mangogna, M., McGinnis, K., Medlin, L.K., Montsant, A., Secq, M.-P.O., Napoli, C., Obornik, M., Parker, M.S., Petit, J.-L., Porcel, B.M., Poulsen, N., Robison, M., Rychlewski, L., Rynearson, T.A., Schmutz, J., Shapiro, H., Siaut, M., Stanley, M., Sussman, M.R., Taylor, A.R., Vardi, A., von Dassow, P., Vyverman, W., Willis, A., Wyrwicz, L.S., Rokhsar, D.S., Weissenbach, J., Armbrust, E.V., Green, B.R., Van de Peer, Y., Grigoriev, I.V., 2008. The Phaeodactylum genome reveals the evolutionary history of diatom genomes. Nature 456, 239-244. doi:10.1038/nature07410

Brembu, T., Jørstad, M., Winge, P., Valle, K.C., Bones, A.M., 2011. Genome-Wide Profiling of Responses to Cadmium in the Diatom Phaeodactylum tricornutum. Environ. Sci. Technol. 45, 7640-7647. doi:10.1021/es2002259

Brooks, A.N., Reiss, D.J., Allard, A., Wu, W.-J., Salvanha, D.M., Plaisier, C.L., Chandrasekaran, S., Pan, M., Kaur, A., Baliga, N.S., 2014. A system-level model for the microbial regulatory genome. Mol. Syst. Biol. 10, 740. 
Carvalho, R.N., Bopp, S.K., Lettieri, T., 2011. Transcriptomics Responses in Marine Diatom Thalassiosira pseudonana Exposed to the Polycyclic Aromatic Hydrocarbon Benzo[a]pyrene. PLoS ONE 6, e26985. doi:10.1371/journal.pone.0026985

Chauton, M.S., Winge, P., Brembu, T., Vadstein, O., Bones, A.M., 2013.Gene Regulation of Carbon Fixation, Storage, and Utilization in the Diatom Phaeodactylum tricornutum Acclimated to Light/Dark Cycles. Plant Physiol. 161, 1034-1048. doi:10.1104/pp.112.206177

Danziger, S.A., Ratushny, A.V., Smith, J.J., Saleem, R.A., Wan, Y., Arens, C.E., Armstrong, A.M., Sitko, K., Chen, W.-M., Chiang, J.-H., Reiss, D.J., Baliga, N.S., Aitchison, J.D., 2014. Molecular mechanisms of system responses to novel stimuli are predictable from public data. Nucleic Acids Res. 42, 1442-1460. doi:10.1093/nar/gkt938

Eisen, M.B., Spellman, P.T., Brown, P.O., Botstein, D., 1998. Cluster analysis and display of genome-wide expression patterns. Proc. Natl. Acad. Sci. 95, 14863-14868.

Franco-Zorrilla, J.M., López-Vidriero, I., Carrasco, J.L., Godoy, M., Vera, P., Solano, R., 2014.DNA-binding specificities of plant transcription factors and their potential to define target genes. Proc. Natl. Acad. Sci. 111, 2367-2372. doi:10.1073/pnas.1316278111

Grigoriev, I.V., Nordberg, H., Shabalov, I., Aerts, A., Cantor, M., Goodstein, D., Kuo, A., Minovitsky, S., Nikitin, R., Ohm, R.A., Otillar, R., Poliakov, A., Ratnere, I., Riley, R., Smirnova, T., Rokhsar, D., Dubchak, I., 2011. The Genome Portal of the Department of Energy Joint Genome Institute.Nucleic Acids Res. gkr947.doi:10.1093/nar/gkr947

Gupta, S., Stamatoyannopoulos, J.A., Bailey, T.L., Noble, W.S., 2007. Quantifying similarity between motifs. Genome Biol. 8, R24.doi:10.1186/gb-2007-8-2-r24

Hennon, G.M.M., Ashworth, J., Groussman, R.D., Berthiaume, C., Morales, R.L., Baliga, N.S., Orellana, M.V., Armbrust, E.V., 2015. Diatom acclimation to elevated CO2 via cAMPsignalling and coordinated gene expression. Nat. Clim. Change 5, 761765.doi:10.1038/nclimate2683

Hook, S.E., Osborn, H.L., 2012. Comparison of toxicity and transcriptomic profiles in a diatom exposed to oil, dispersants, dispersed oil. Aquat. Toxicol. Amst. Neth. 124-125, 139151. doi:10.1016/j.aquatox.2012.08.005

Kalinka, A.T., 2013. The probability of drawing intersections: extending the hypergeometric distribution. ArXiv13050717 Math.

Keeling, P.J., Burki, F., Wilcox, H.M., Allam, B., Allen, E.E., Amaral-Zettler, L.A., Armbrust, E.V., Archibald, J.M., Bharti, A.K., Bell, C.J., Beszteri, B., Bidle, K.D., Cameron, C.T., Campbell, L., Caron, D.A., Cattolico, R.A., Collier, J.L., Coyne, K., Davy, S.K., Deschamps, P., Dyhrman, S.T., Edvardsen, B., Gates, R.D., Gobler, C.J., Greenwood, S.J., Guida, S.M., Jacobi, J.L., Jakobsen, K.S., James, E.R., Jenkins, B., John, U., Johnson, M.D., Juhl, A.R., Kamp, A., Katz, L.A., Kiene, R., Kudryavtsev, A., Leander, B.S., Lin, S., Lovejoy, C., Lynn, D., Marchetti, A., McManus, G., Nedelcu, A.M., MendenDeuer, S., Miceli, C., Mock, T., Montresor, M., Moran, M.A., Murray, S., Nadathur, G., Nagai, S., Ngam, P.B., Palenik, B., Pawlowski, J., Petroni, G., Piganeau, G., Posewitz, M.C., Rengefors, K., Romano, G., Rumpho, M.E., Rynearson, T., Schilling, K.B., Schroeder, D.C., Simpson, A.G.B., Slamovits, C.H., Smith, D.R., Smith, G.J., Smith, S.R., Sosik, H.M., Stief, P., Theriot, E., Twary, S.N., Umale, P.E., Vaulot, D., Wawrik, B., Wheeler, G.L., Wilson, W.H., Xu, Y., Zingone, A., Worden, A.Z., 2014. The Marine Microbial Eukaryote Transcriptome Sequencing Project (MMETSP): illuminating the functional diversity of eukaryotic life in the oceans through transcriptome sequencing. PLoS Biol. 12, e1001889. doi:10.1371/journal.pbio.1001889

Kustka, A.B., Milligan, A.J., Zheng, H., New, A.M., Gates, C., Bidle, K.D., Reinfelder, J.R., 2014. Low $\mathrm{CO} 2$ results in a rearrangement of carbon metabolism to support $\mathrm{C} 4$ photosynthetic carbon assimilation in Thalassiosira pseudonana. New Phytol. 204, 507520.doi:10.1111/nph.12926 
390

391

392

393

394

395

396

397

398

399

400

401

402

403

404

405

406

407

408

409

410

411

412

413

414

415

416

417

418

419

420

421

422

423

424

425

426

427

428

429

430

431

432

433

434

435

436

437

438

439

Levitan, O., Dinamarca, J., Zelzion, E., Lun, D.S., Guerra, L.T., Kim, M.K., Kim, J., Van Mooy, B.A.S., Bhattacharya, D., Falkowski, P.G., 2015. Remodeling of intermediate metabolism in the diatom Phaeodactylum tricornutum under nitrogen stress. Proc. Natl. Acad. Sci. U. S. A. 112, 412-417. doi:10.1073/pnas.1419818112

Marchler-Bauer, A., Derbyshire, M.K., Gonzales, N.R., Lu, S., Chitsaz, F., Geer, L.Y., Geer, R.C., He, J., Gwadz, M., Hurwitz, D.I., Lanczycki, C.J., Lu, F., Marchler, G.H., Song, J.S., Thanki, N., Wang, Z., Yamashita, R.A., Zhang, D., Zheng, C., Bryant, S.H., 2015. CDD: NCBI's conserved domain database. Nucleic Acids Res. 43, D222226.doi:10.1093/nar/gku1221

Mock, T., Samanta, M.P., Iverson, V., Berthiaume, C., Robison, M., Holtermann, K., Durkin, C., Bondurant, S.S., Richmond, K., Rodesch, M., Kallas, T., Huttlin, E.L., Cerrina, F., Sussman, M.R., Armbrust, E.V., 2008. Whole-genome expression profiling of the marine diatom Thalassiosira pseudonana identifies genes involved in silicon bioprocesses.

Proc. Natl. Acad. Sci. U. S. A. 105, 1579-1584. doi:10.1073/pnas.0707946105

Müllner, D., 2013.Fastcluster: Fast Hierarchical, Agglomerative Clustering Routines for R and Python. J. Stat. Softw. 53, 1-18.

Nymark, M., Valle, K.C., Brembu, T., Hancke, K., Winge, P., Andresen, K., Johnsen, G., Bones, A.M., 2009. An Integrated Analysis of Molecular Acclimation to High Light in the Marine Diatom Phaeodactylum tricornutum. PLoS ONE 4, e7743. doi:10.1371/journal.pone.0007743

Nymark, M., Valle, K.C., Hancke, K., Winge, P., Andresen, K., Johnsen, G., Bones, A.M., Brembu, T., 2013.Molecular and Photosynthetic Responses to Prolonged Darkness and Subsequent Acclimation to Re-lllumination in the Diatom Phaeodactylum tricornutum.PLoS ONE 8, e58722. doi:10.1371/journal.pone.0058722

Pelham, H., 1985. Activation of heat-shock genes in eukaryotes. Trends Genet. 1, 31-35. doi:10.1016/0168-9525(85)90012-5

Peterson, E.J.R., Reiss, D.J., Turkarslan, S., Minch, K.J., Rustad, T., Plaisier, C.L., Longabaugh, W.J.R., Sherman, D.R., Baliga, N.S., 2014.A high-resolution network model for global gene regulation in Mycobacterium tuberculosis. Nucleic Acids Res. 42, 11291-11303. doi:10.1093/nar/gku777

Reiss, D.J., Baliga, N.S., Bonneau, R., 2006. Integrated biclustering of heterogeneous genomewide datasets for the inference of global regulatory networks. BMC Bioinformatics 7 , 280. doi:10.1186/1471-2105-7-280

Sapriel, G., Quinet, M., Heijde, M., Jourdren, L., Tanty, V., Luo, G., Le Crom, S., Lopez, P.J., 2009. Genome-Wide Transcriptome Analyses of Silicon Metabolism in Phaeodactylum tricornutum Reveal the Multilevel Regulation of Silicic Acid Transporters. PLoS ONE 4, e7458. doi:10.1371/journal.pone.0007458

Shrestha, R.P., Tesson, B., Norden-Krichmar, T., Federowicz, S., Hildebrand, M., Allen, A.E., 2012. Whole transcriptome analysis of the silicon response of the diatom Thalassiosira pseudonana. BMC Genomics 13, 499. doi:10.1186/1471-2164-13-499

Suzuki, R., Shimodaira, H., 2006. Pvclust: an R package for assessing the uncertainty in hierarchical clustering. Bioinformatics 22, 1540-1542. doi:10.1093/bioinformatics/btl117

Szklarczyk, D., Franceschini, A., Kuhn, M., Simonovic, M., Roth, A., Minguez, P., Doerks, T., Stark, M., Muller, J., Bork, P., Jensen, L.J., von Mering, C., 2011. The STRING database in 2011: functional interaction networks of proteins, globally integrated and scored. Nucleic Acids Res. 39, D561-568.doi:10.1093/nar/gkq973

Thamatrakoln, K., Bailleul, B., Brown, C.M., Gorbunov, M.Y., Kustka, A.B., Frada, M., Joliot, P.A., Falkowski, P.G., Bidle, K.D., 2013. Death-specific protein in a marine diatom regulates photosynthetic responses to iron and light availability. Proc. Natl. Acad. Sci. U. S. A. $110,20123-20128$. doi:10.1073/pnas. 1304727110 
Thamatrakoln, K., Korenovska, O., Niheu, A.K., Bidle, K.D., 2012. Whole-genome expression analysis reveals a role for death-related genes in stress acclimation of the diatom Thalassiosira pseudonana. Environ. Microbiol. 14, 67-81. doi:10.1111/j.14622920.2011.02468.x

Troyanskaya, O., Cantor, M., Sherlock, G., Brown, P., Hastie, T., Tibshirani, R., Botstein, D., Altman, R.B., 2001. Missing value estimation methods for DNA microarrays. Bioinforma. Oxf. Engl. 17, 520-525.

Tsuda, A., Takeda, S., Saito, H., Nishioka, J., Nojiri, Y., Kudo, I., Kiyosawa, H., Shiomoto, A., Imai, K., Ono, T., Shimamoto, A., Tsumune, D., Yoshimura, T., Aono, T., Hinuma, A., Kinugasa, M., Suzuki, K., Sohrin, Y., Noiri, Y., Tani, H., Deguchi, Y., Tsurushima, N., Ogawa, H., Fukami, K., Kuma, K., Saino, T., 2003. A Mesoscale Iron Enrichment in the Western Subarctic Pacific Induces a Large Centric Diatom Bloom. Science 300, 958961. doi:10.1126/science. 1082000

Valle, K.C., Nymark, M., Aamot, I., Hancke, K., Winge, P., Andresen, K., Johnsen, G., Brembu, T., Bones, A.M., 2014.System Responses to Equal Doses of Photosynthetically Usable Radiation of Blue, Green, and Red Light in the Marine Diatom Phaeodactylum tricornutum.PLoS ONE 9, e114211. doi:10.1371/journal.pone.0114211 